\title{
COMMUNITY HETEROGENEITY AND THE EVOLUTION OF INTERACTIONS BETWEEN PLANTS AND INSECT HERBIVORES
}

\author{
Anurag A. Agrawal \\ Department of Ecology and Evolutionary Biology and Department of Entomology, Cornell University \\ Ithaca, New York 14853-2701 USA \\ E-MAIL: AA337@CORNELL.EDU
}

JeNNifER A. LAU

Department of Plant Biology, University of Minnesota

St. Paul, Minnesota 55108 USA

E-MAIL: LAUXXo87@UMn.EDU

Peter A. Hambäck

Department of Botany, Stockholm University

SE-106 91 Stockholm Sweden

E-MAIL: PETER.HAMBACK@BOTAN.SU.SE

KEYWORDS

associational resistance, coevolution, community ecology, community genetics, diffuse selection, diversity, herbivory, invasive species, plant apparency, plant defense guild hypothesis, plant-herbivore interactions, quantitative genetics

\begin{abstract}
Plant communities vary tremendously in terms of productivity, species diversity, and genetic diversity within species. This vegetation heterogeneity can impact both the likelihood and strength of interactions between plants and insect herbivores. Because altering plant-herbivore interactions will likely impact the fitness of both partners, these ecological effects also have evolutionary consequences. We review several hypothesized and well-documented mechanisms whereby variation in the plant community alters the plant-herbivore interaction, discuss potential evolutionary outcomes of each of these ecological effects, and conclude by highlighting several avenues for future research. The underlying theme of this review is that the neighborhood of plants is an important determinant of insect attack, and this results in feedback effects on the plant community. Because plants exert selection on herbivore traits and, reciprocally, herbivores exert selection on plant-defense traits, variation in the plant community likely contributes to spatial and temporal variation in both plant and insect traits, which could influence macroevolutionary patterns.
\end{abstract}

The Quarterly Review of Biology, December 2006, Vol. 81, No. 4 Copyright (C) 2006 by The University of Chicago. All rights reserved.

0033-5770/2006/8104-0002\$15.00 


\section{INTRODUCTION AND HISTORY}

$\mathbf{A}^{\mathrm{s}}$ STRIKING feature of most plant and animal communities is that the organisms are unevenly distributed in nature. This phenomenon, which occurs across all spatial scales, has the additional consequence that the strength and identity of interactions between species show a high degree of spatial variability. As a consequence of individuals moving across space or from spatial variability in population growth rates, individuals of the same species typically encounter different interactions at different sites. The study of such spatial variability is a central issue within ecology, as it enters most definitions of the subject, and has attracted interest from ecologists since the early days. This paper deals with these spatial patterns in communities and considers their evolutionary consequences for interactions between insect herbivores and plants.

Given that plant communities vary somewhat predictably in their diversity, structure, and composition across habitats and biogeographic zones (Gurevitch et al. 2002), it is a reasonable hypothesis that the strength of plant-herbivore interactions may also vary predictably. For example, at a global scale, it has been hypothesized that there is a latitudinal gradient in the intensity of herbivory, which has favored a greater diversity of unpalatable plants closer to the equator compared to temperate regions (Pennings and Silliman 2005). It also has been argued that herbivores have evolved more specialized strategies in diverse tropical habitats compared to temperate regions due to heterogeneity in the chemical and ecological traits associated with particular plant species. Though the bulk of research in plant-insect interactions over the past decades has focused on binary interactions independent of the surrounding community matrix, it is becoming increasingly clear that the plant community as a whole can shape the selective environment for both plants and herbivores. Plant communities show a high level of variation in genetic diversity, overall biomass, species richness, and relative abundance. This variation creates physical and chemical heterogeneity, which can strongly impact the interaction between plants and herbivores.

While the interest in the role of spatial complexity in plant-herbivore interactions may be as old as agriculture, as evidenced by the widespread traditional use of intercropping to reduce pest attack, theories to explain these patterns did not begin to mature until the 1960s. During this time, four somewhat parallel debates involved the role of plant spatial heterogeneity on plant-herbivore interactions: (i) effects of plant species diversity on herbivore population stability; (ii) effects of plant stand characteristics on herbivore impacts; (iii) consequences of plant apparency for the evolution of plant defenses; and (iv) associations of plants into guilds that represented community defenses. Below we provide a brief overview of the main concepts that shaped this early research. We use these ideas, along with more recent hypotheses, as the foundation for linking heterogeneity in plant communities to the evolution of plantherbivore interactions (Box 1, Tables 1 and 2).

\section{DIVERSITY AND STABILITY}

Resource diversity has long been predicted to increase community stability, in part by reducing runaway consumption of plants. Charles Elton (1958) proposed the first hypothesis to explain how simple plant communities can incur greater losses to herbivory than diverse habitats. Based on a combination of theoretical results and empirical observations, he suggested that the reduced herbivory in complex habitats was a consequence of the higher efficiency of predaceous insects in these environments (Enemies Hypothesis). The suggested reason for this efficiency is that greater diversity of alternative food sources and habitats increases the persistence and stability of generalist predators. Based on the classic experiment by Carl Huffaker (1958), spatial complexity was argued to enable predator-prey interactions to avoid collapse due to predators consuming all prey individuals. Elton contrasted low diversity habitats such as agricultural fields and temperate forests, where pest outbreaks frequently occur, to high diversity tropical rainforests, where out- 


\section{Box 1 \\ Definitions of vegetation heterogeneity effects on plant-herbivore interactions}

Associational resistance: Plants experience reduced herbivory when growing in close proximity to highly defended neighbors or to plants that physically or chemically mask the focal plant, compared to when growing next to other (or no) plants (Hambäck et al. 2000).

Associational susceptibility: Plants experience increased herbivory when growing in close proximity to preferred host plants or plants that provide alternate resources for herbivores, compared to when growing next to less preferred plants (Agrawal 2004).

Enemy-free space: An herbivore experiences reduced predation or parasitism when feeding on a particular host plant. Typically, it is assumed that enemy-free space comes at the cost of reduced host plant quality (Murphy 2004).

Host alternation: An insect herbivore population requires two different host plant species to complete its lifecycle (Dixon and Kundu 1994).

Neural constraints hypothesis: Diverse plant communities make host choice problematic for herbivores by causing greater strain on neural processing, which results in either inefficient decision-making (i.e., exposing organisms to predation or other risks) or poor quality decision-making (i.e., choosing plants on which the herbivore has low fitness) (Bernays 2001).

Plant apparency hypothesis: Apparent plants are more likely to be defended by quantitative defenses, which typically reduce plant digestability and are not easily overcome by specialist herbivores; unapparent plants are more likely to be defended by qualitative defenses, typically toxins that limit feeding to subset of specialized herbivores (Feeny 1976).

Plant defense guild hypothesis: Plants in a community are functionally interdependent with respect to their herbivores, implying that vegetation composition can influence herbivore attack rates and ultimately plant and herbivore evolution (Atsatt and Odowd 1976).

Plant resource competition: The presence of plant competitors alters several environmental variables (e.g., water, light nutrients, available space) that may influence the costs or benefits of producing plant defenses (Tiffin 2002). This effect is, in part, mediated by a proposed tradeoff between defense and competitive ability.

Plant resistance to herbivory: Traits of the plant that reduce the preference or performance of herbivores (Karban and Baldwin 1997) and that are expected to reduce herbivory. Resistance traits may be chemical, morphological, or phenological in nature and may be expressed constitutively (all of the time) or induced following attack by herbivores.

Refuge hypothesis: The presence of susceptible plants in a primarily resistant population may reduce selection on herbivore counteradaptations (Gould 2003).

Tolerance to herbivory: The degree to which plant fitness is affected by herbivore damage relative to fitness in the undamaged state (Strauss and Agrawal 1999). When damage levels are continuous, tolerance is measured as the slope of the line relating plant fitness to the level of damage. If damage is experimentally imposed at a single level, or if it is qualitative (such as loss of the apical meristem), then tolerance is typically measured as the ratio of plant fitness in the damaged to the undamaged state. 


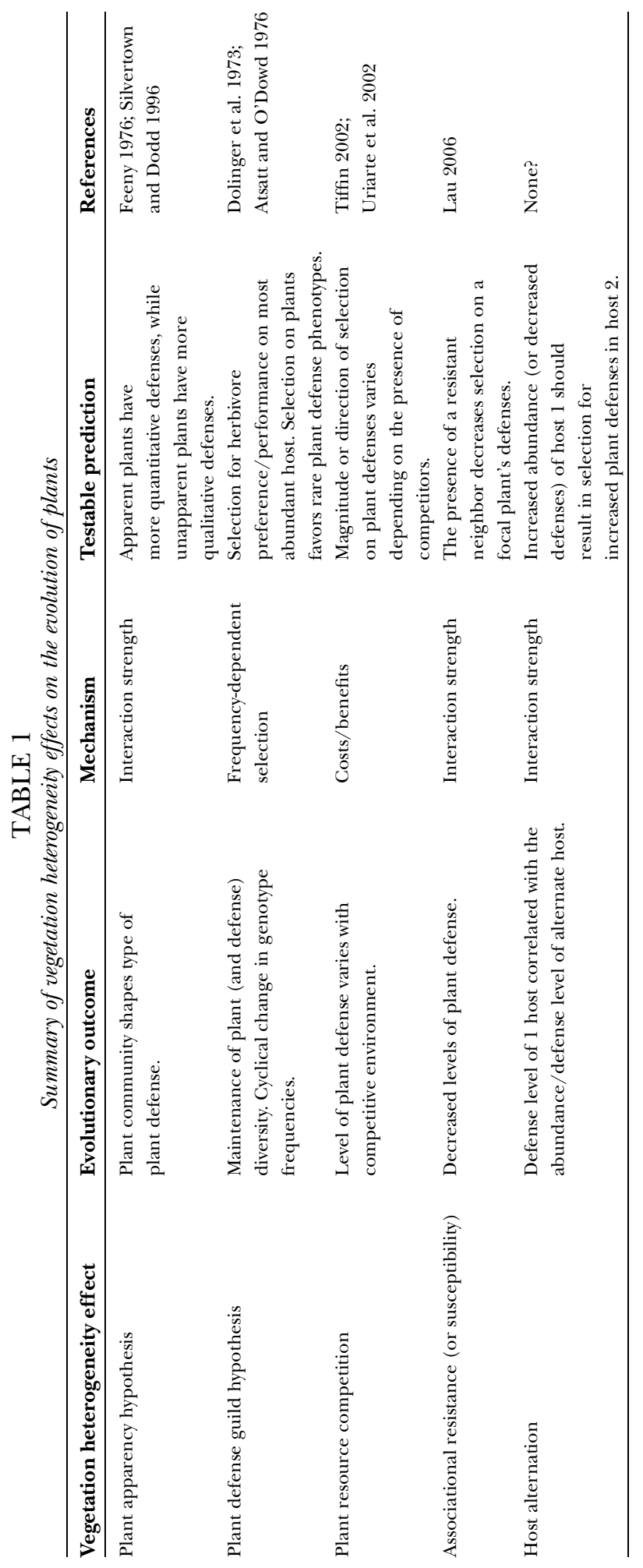




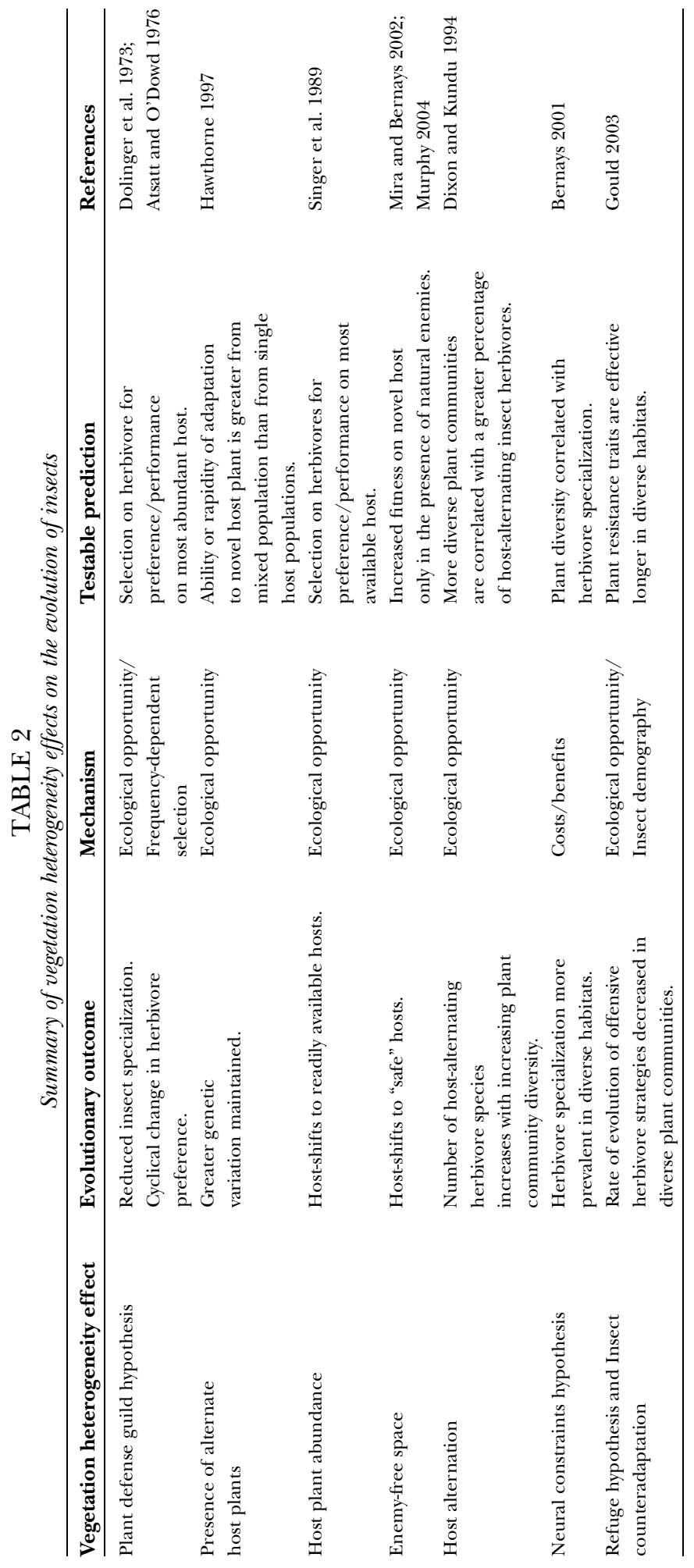


breaks are purportedly less common. Thus, through mechanisms of greater predator efficiency and population persistence, community stability may be enhanced by plant diversity.

\section{EFFECTS OF STAND CHARACTERISTICS ON HERBIVORE ABUNDANCE AND IMPACT}

In contrast to the Enemies Hypothesis, Richard Root (1973) argued that the higher herbivore densities in dense, monospecific, or large stands emerge as a consequence of resource concentration effects on immigration and emigration of insect herbivores. This Resource Concentration Hypothesis posits that individuals are more likely to locate and remain in stands with dense host plants. Moreover, the tendency to remain in a patch was argued to be higher for specialized insect herbivores compared to generalized ones because a species with a broader host range would be more likely to drift into the surrounding vegetation to feed on other host plants. The Resource Concentration Hypothesis and the Enemies Hypothesis have become the two main hypotheses used to explain lower herbivore loads in diverse agricultural stands (Russell 1989; Andow 1991; Tonhasca and Byrne 1994; Bommarco and Banks 2003). Recent studies suggest that resource concentration effects are also important in natural systems, and perhaps have greater predictive ability than plant productivity for understanding the effects of insect herbivory on plant community composition (Long et al. 2003; Carson et al. 2004). A consequence of both these hypotheses is that the herbivore loads on a focal plant may be highly context dependent. For example, one plant species may indirectly receive protection from herbivory by associating with other plants; the main term associated with this pattern is "associational resistance" (Tahvanainen and Root 1972). Of course, several other effects of plant associations are possible and are detailed in Box 1.

\section{PLANT APPARENCY AND THE EVOLUTION OF PLANT DEFENSES}

The third concept arose as an evolutionary consequence of the Resource Concentration Hypothesis, and concerned the role of plant apparency in the evolution of plant defenses, herbivore search strategies, and diet breadth. This discussion was initiated by Paul Feeny (1976), who observed that highly apparent plants tend to have different plant chemistry than seemingly unapparent plants. In particular, apparency theory suggests that longlived plants, large plants, or plants growing in low diversity communities, will evolve defenses that are effective against most all consumers, and function by reducing the edibility or nutritional quality of the plant. Temperate trees typify such apparent plants because of their lifespan, size, and community structure. Thus, oak trees are defended by low levels of foliar nitrogen and water and high levels of leaf toughness and tanninsconsidered quantitative defenses because they act in a dose-dependent manner on both generalist and specialist herbivores. These plants are predicted not to defend with acute toxins or barriers to feeding (qualitative defenses), which are typically found in unapparent plants. Qualitative barriers to feeding in herbaceous unapparent plants (such as alkaloids, cyanides, and cardenolides) are readily overcome by specialists herbivores (e.g., cardenolides in milkweeds, Holzinger and Wink 1996). The interplay between ecology and evolution is intriguing; given that unapparent plants are difficult to find for specialists (Root 1973), these plants have the evolutionary advantage of hiding from their most damaging enemies. Apparent plants, though a concentrated resource, are of poor quality for nearly all consumers. The general pattern of divergent patterns of chemical defense in apparent and unapparent plants has stood the test of time (Silvertown and Dodd 1996).

Feeny suggested that the mechanism underlying the difference between apparent and unapparent plants was that highly apparent plants are more likely to experience continuously high herbivory because they are easier to locate, and this would necessitate the development of general defenses effective against most all consumers. Conversely, the low and irregular herbivore attack rates on unapparent plants was assumed to reduce selection for more effective defenses; in other words, the qualitative barriers to feeding were sufficient. An early criticism against this view 
was that counteradaptations in herbivore search behavior should reduce the difference in attack rates between apparent and unapparent plants (Rausher 1978). The argument was that specialist insects searching for unapparent plants would experience strong selection for increased host search efficiency. Indeed, many specialist herbivores of unapparent plants use defense-related, long-distance cues to locate their hosts (Bowers 1991; Giamoustaris and Mithen 1995). In addition, qualitative defenses are often breached by generalist herbivores and can still have dose-dependent effects on specialist herbivores (Agrawal 1998, 1999; Agrawal and Kurashige 2003). Nonetheless, despite questionable mechanisms, apparency theory provides a useful framework for thinking about the evolution of plant chemical defense in the context of plant community heterogeneity.

\section{THE PLANT DEFENSE GUILD HYPOTHESIS}

The interdependency of plants, in relation to their interaction with herbivores, prompted Peter Atsatt and Dennis O'Dowd (1976) to formulate general ideas about plant defense guilds, describing several mechanisms underlying how plant neighbors impact attack rates of focal plant species (Tables 1 and 2). Atsatt and O'Dowd (1976) introduced three potential underlying mechanisms: insectary, repellent, and attractant-decoy plants. Because these ecological mechanisms underlie the potential for evolutionary consequences detailed below, we, in turn, evaluate the current status of each.

First, "insectary plants" are those that attract predators of herbivores by providing floral or extrafloral nectaries or alternate herbivore hosts. These predators feed on herbivores on the insectary plants but, may also feed on herbivores attacking plant neighbors. Insectary plants have widely been employed in agriculture as part of the general principle that plant diversification typically enhances predation and parasitism of target pests (Russell 1989; Gurr et al. 2003). Two recent studies in natural systems have also demonstrated that plants that host herbivores and parasitoids increase parasitism of herbivores on neighboring plants (Stiling et al. 2003; Morris et al. 2004). Thus, insectary plants can be viewed as an update of Elton's Enemies Hypothesis, with the notion that specific plant species are better neighbors than others.

Second, "repellent plants" are plants that deter herbivores via spines, toxins, odors, or shade, causing herbivores to reject or fail to locate their host plant in the neighborhood. The proposal of repellent plants is the most general prediction of Atsatt and O'Dowd (1976), with many examples indicating strong influences on plant community structure. Examples of associational resistance mediated by repellent plants abound from both the marine and terrestrial literature on both vertebrate and invertebrate herbivores (Hay 1986; Pfister and Hay 1988; Callaway 1995; Hambäck et al. 2000; Callaway et al. 2005). This repellent plants hypothesis was later split into two mechanisms, "masking" (a host plant is not detectable because of the presence of nonhosts) and "repellency" (active avoidance by herbivores of the repellant plant) (Hambäck and Beckerman 2003).

Third, "attractant-decoy" plants are those that can serve as alternative food sources to the herbivore, and by their presence reduce the herbivore impact on other plants in the neighborhood. This hypothesis later served as a founding principle behind the development of trap cropping systems in agriculture (Vandermeer 1989). It has largely been rejected as a mechanism in natural plant-insect systems, however, because it neglects the numerical response of herbivores at larger spatial scales and assumes suboptimal food selection by herbivores (Hjältén et al. 1993; White and Whitham 2000; Rousset and Lepart 2002; Hambäck and Beckerman 2003; Rand 2003). Nonetheless, attractant-decoy dynamics may be common in natural systems for plant interactions with large mobile generalist grazers (Milchunas and Noy-Meir 2002).

The attractant-decoy hypothesis can also be seen as a precursor to ideas on the effects of plant mixtures for generalist herbivores, because it identified the possibility that plant neighbors may not only reduce, but also enhance herbivory on a focal plant. This can occur, for example, when herbivore populations grow on an attractive plant and spill over 
onto neighboring vegetation. In the current ecological literature, the main terms associated with such negative effects between plants are "apparent competition" (Connell 1990; Holt and Lawton 1994) and "associational susceptibility” (Brown and Ewel 1987). A recent set of conceptual observations suggests that the direction of associational effects may be predicted based on two axes, the level of host plant specialization and the extent of resources provided by plant neighbors (Figure 1) (Agrawal 2004). Associational effects on a focal plant are predicted to increasingly move from susceptibility to resistance as neighbor host quality decreases for generalist herbivores, or as alternate resources are not provided for specialist herbivores.

\section{EVOLUTIONARY IMPACTS OF VEGETATION HETEROGENEITY ARE LIKELY COMMON}

Ample evidence exists that vegetation heterogeneity can modify the probability of a particular plant-herbivore interaction occurring and the intensity of that interaction. In current community ecology jargon, these types of interactions are variously described as indirect, trait-mediated, or interaction modifications (Wootton 1994; Abrams 1995). If this change in the strength of the interaction alters individual fitness in a nonrandom manner, then vegetation heterogeneity may also alter patterns of natural selection on plant and insect traits involved in the interaction. For the ecological interactions outlined in this review to have evolutionary consequences, the traits of interest (in the plants or insects) must meet the Darwinian criterion of having heritable variation that affects fitness. Nearly all continuously varying traits exhibit genetic variance within and between populations, and thus the real challenge becomes identifying the selective agents, fitness impacts (i.e., strength and direction of selection), and factors that may limit a response to selection. Below, we focus on microevolutionary responses in terms of how plant neighborhood may alter selection on both plants and herbivores. Later, we discuss how these responses could shape macroevolutionary patterns.

While early studies of coevolution often fo- cused on tightly linked pairs of interacting species, both Daniel Janzen (1980) and Laurel Fox (1981) wrote of "diffuse coevolution"-situations where reciprocal selection occurred between groups of plants and groups of herbivorous insects. In particular, Fox predicted that diffuse coevolution was most likely for organisms like temperate forest trees, with each individual exposed to many damaging herbivores over its lifetime. For example, in a plant community with several congeneric plants, several herbivore species may attack each plant species, and there is likely some overlap in the attackers on closely related plants. Thus, each plant species may be evolving resistance, but to a suite of herbivore species. Similarly, each herbivore species may be evolving offense strategies, but these adaptations are shaped by a set of host plants. Because of ecological interactions between these suites of interacting community members, and because of tradeoffs and constraints produced by the necessity of adapting to several selective agents simultaneously, the net selection on a trait will thus depend on the composition of the community.

\section{The Plant Community's Role in the Evolution of Plant Defenses}

Interactions among plants may influence the evolution of plant defenses in many ways. We focus primarily on how competing plants change environmental variables, such as resource availability, that in turn affect the shape of the fitness landscape. We also discuss how interactions between plants influence the evolution of plant defenses by directly altering the probability of herbivore attack. For example, resource competition may affect selection on defense by altering the costs of plant defenses, influencing the expression of plant defense traits, or changing the fitness consequences of herbivore damage. We discuss the evidence for each mechanism and how competitors and herbivores interact to modify patterns of selection on plant defenses. Competitors may also influence selection on plant defenses if there are genetic correlations or pleiotropic effects between traits involved in the competitive and plantherbivore interactions; however, we will limit 


\section{Resource used from neighboring plants}

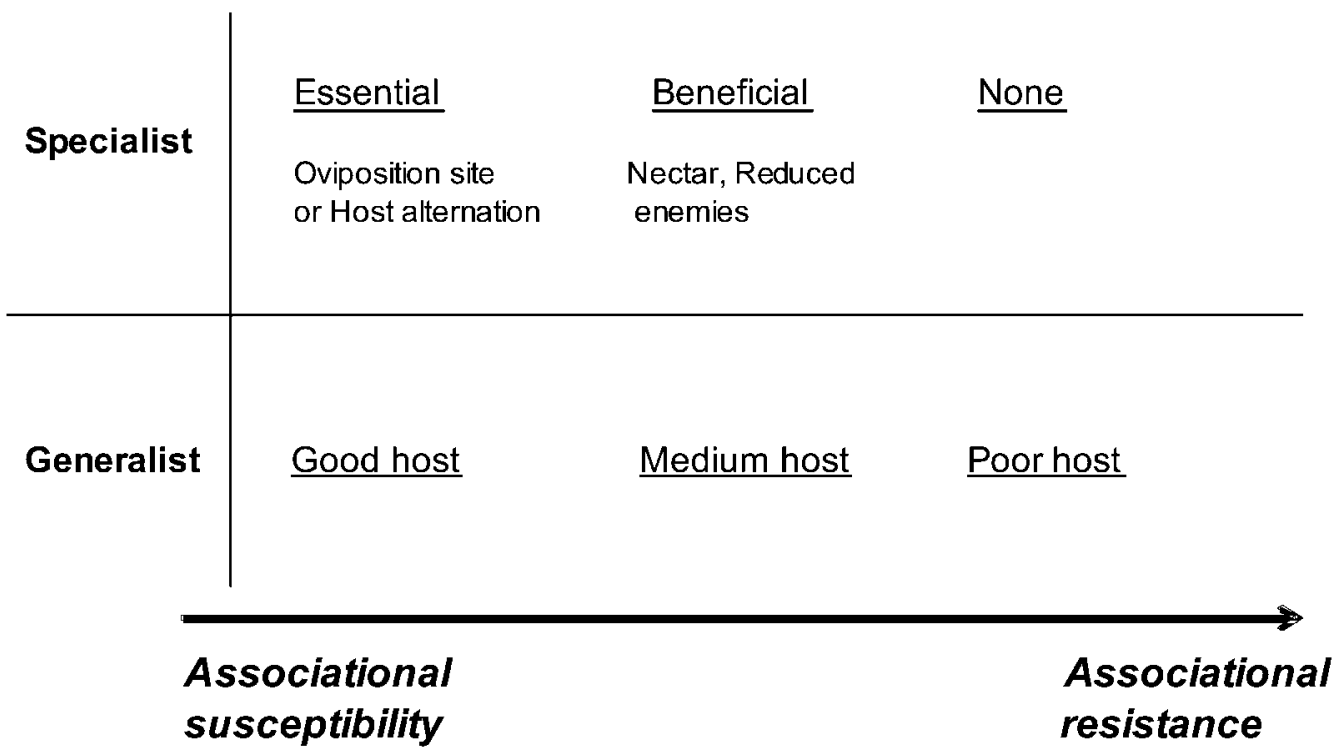

Figure 1. Predicting Associational Effects

Associational effects of plant neighbors are predicted to be determined by the diet breadth of insect herbivores and the extent to which the neighboring plants are utilized. Resources gained from plant neighbors extend beyond food resources. Thus, as specialists gain less from neighbors, focal plants are increasingly predicted to provide associational resistance. For generalist herbivores, as the quality of neighboring plants declines from a good host to poor host, so will the associational effect on a focal plant change from susceptibility to resistance. (Adapted from Agrawal 2004.)

our discussion to evolutionary consequences arising from ecological effects (see Iwao and Rausher 1997 for a discussion of effects due to genetic architecture). While we focus on negative relationships between plants in this section, positive plant-plant interactions (i.e., facilitation) could also produce evolutionary effects and deserve further attention.

Competition is often thought to increase the costs of defense (i.e., a reduction in plant fitness associated with defense in absence of herbivores) because competing plants have fewer resources available for allocation to defense compared to plants growing without competitors. Although this prediction has been confirmed in phenotypic studies (i.e., studies that have estimated the cost of induced responses to herbivory in the presence and absence of competitors) (van Dam and Baldwin 1998; Agrawal 2000), the reverse has been found for quantitative genetic studies of costs of constitutive defenses (Siemens et al. 2002, 2003; Tiffin 2002; Julia Koricheva, personal communication). Thus, the presence of competitors does indeed alter the costs of defense, though there is still no generality regarding the direction of the effect, and this requires further study. We nonetheless agree with the general prediction that the presence of competitors will alter selection on plant defenses due to changes in the resource investment strategy.

Also, competition can alter the phenotypic expression of plant defense traits, which alters the variation on which selection can act. Such indirect effects are often referred to as "trait-mediated" because the presence of competitors changes the plant phenotype (i.e., phenotypic plasticity) in a manner that influences levels of herbivore attack (Agrawal 2001; Callaway et al. 2003). Changes may occur directly in defense traits or in other traits that influence herbivore attack, such as leaf physiology or plant architecture (Morgan and 
Smith 1981; Kurashige and Agrawal 2005). For example, Richard Karban et al. (1989) demonstrated that cotton plants express lower levels of induced resistance when growing in highly competitive environments compared to less competitive ones. Such effects may be due to resource availability (Cipollini and Bergelson 2001) or plant responses to competitors irrespective of resources (Kurashige and Agrawal 2005). Similarly, Agrawal (2004) showed that a combination of plant competition and root herbivory altered leaf miner abundance on milkweed. In this case, while neither competition nor root herbivory alone affected leaf miner abundance, competition and root herbivory combined reduced abundance by $40 \%$ compared to controls. Thus, the interactive effects of plant competition and past herbivore attack may either decrease or increase subsequent plant resistance.

Third, the presence of competitors may alter selection on plant defenses by changing the fitness consequences of herbivore damage. This would occur when the negative fitness impacts of herbivory are intensified in competitive environments because any photosynthetic material removed by herbivores may further limit the plant's ability to compete for limiting resources. In other words, competitors may alter selection on plant defenses (i.e., selection will be diffuse) when interactive fitness effects occur between competition and herbivory, that is, when fitness effects are either synergistic or substitutive. More specifically, selection will be diffuse provided that there are interactive effects on the relationship between plant traits and fitness and not on fitness alone (Strauss and Irwin 2004; Strauss et al. 2005 for a more detailed explanation). However, a recent review demonstrates that only one of ten studies shows synergistic effects of herbivory and competition on focal plants, with a second study showing a substitutive effect, that is, the cumulative effect of herbivory and competition was less than additive (Hambäck and Beckerman 2003). While the low incidence of interactive effects documented in this review suggests that they are rare, additional recent studies demonstrate both synergistic and substitutive interactions between herbivory and competition on plant performance (Agrawal
2004; Lau and Strauss 2005; Linhart et al. 2005). For example, Agrawal (2004) showed that the effects of root-feeding herbivores and competition were greater than additive (i.e., synergistic) in reducing components of fitness, potentially leading to more intense selection for plant defenses in the presence of competitors. This result also raises the possibility that selection for traits that reduce competition may be an alternative evolutionary response to the joint selective pressures of competitors and herbivores. In contrast, Yan Linhart et al. (2005) showed that aphid herbivores on thyme only decrease plant growth and reproduction in the absence of competition. Because aphids differentially affect the fitness of particular plant chemotypes (which are genetically determined), selective pressures imposed by aphid herbivores on plant defenses will likely vary with the competitive environment.

The three mechanisms by which competitors affect selection on plant defenses may, of course, act simultaneously. For example, in the milkweed system, competition alters the phenotypic expression of plant defenses as well as the fitness effects of herbivory (Agrawal 2004). To determine the net effect of these mechanisms, however, the intensity of natural selection on plant defenses must be measured in the various competitive environments. The first rigorous examination of selection on plant defense as influenced by plant neighborhood was conducted by Peter Tiffin (2002). Consistent with plant allocation theory (Strauss and Agrawal 1999), Tiffin found that common morning glory plants (Ipomoea purpurea) were less tolerant of herbivore damage when grown in high competition environments than in low competition ones. Given that Tiffin also reported that genetic families of the morning glory varied in their fitness and defense levels, it is reasonable to ask how competition affected selection on plant defenses. Tiffin found no evidence, however, that selection on resistance or tolerance was affected by plant competitors.

Only a few theoretical investigations have considered the effects of plant competition on selection for plant defense. A combination of simulations and analytical results by Arthur 
Weis and Michael Hochberg (2000) demonstrated that plant competition can indeed alter selection on defense. This occurs, in part, because herbivory not only damages a susceptible plant, but resistant plants may seize resources and then further suppress the fitness of susceptible individuals. Not surprisingly, the authors found that the type of competition (symmetric versus asymmetric) and defense (herbivore avoidance versus reduction in damage once a plant is found) had strong consequences for the evolution of defense. In another theoretical study, the evolution of resistance, as parameterized from empirical data on tall goldenrod (Solidago altissima) from eastern North America, appeared to be independent of competition (Uriarte et al. 2002). In general, selection on the plant was dominated by competition, and resistance was only favored under conditions of very low costs of resistance. The authors conclude that because plant traits associated with competitive ability also tend to enhance tolerance to herbivory (Strauss and Agrawal 1999), Solidago may rely heavily on a tolerance strategy.

While the above reviewed studies assume that effects of plant neighbors on selection for plant defenses largely depend on general plant characteristics, such as plant biomass and growth rate, other studies suggest that the specific identity of the plant competitor may alter selection on plant traits. Lau (2006, unpublished data) recently reported a study demonstrating that an introduced plant, Medicago polymorpha, alters selection for plant defenses in the co-occurring native plant Lotus wrangelianus. An exotic weevil (Hypera brunneipennis), which feeds on both plants, exerts greater damage to native Lotus in the presence of Medicago than in the presence of only the native plant community (Lau and Strauss 2005). This associational effect caused stronger positive directional selection for tolerance to herbivory and competitive ability in the presence of Medicago than in the presence of native plants. Medicago also reduced the selection for resistance in native Lotus, however, which suggests that the presence of Medicago altered the type of defense that was favored. Because Medicago removal treatments did not affect total plant biomass, it appears that these microevolutionary effects were driven by strong species specific effects of Medicago on the Lotus/Hypera interaction.

Juha Tuomi and colleagues (Augner et al. 1991; Tuomi and Augner 1993) took a theoretical approach to model the evolution of plant defense as influenced by neighbor identity. They used game theoretical models to investigate associational effects influencing selection (in addition to competition). In particular, they assume that herbivores not only avoid unpalatable plants, but also neighbors of unpalatable plants. This has the potential to lead to "synergistic selection for defense" (i.e., palatable plants gain a greater advantage than unpalatable plants do when both are neighboring an unpalatable plant) (Tuomi and Augner 1993) or the maintenance of defended and undefended plants in a population (Augner et al. 1991). Unfortunately, like the other entirely theoretical study (Weis and Hochberg 2000), these game theory models predict many possible outcomes of neighboring plants on selection for defense, with few general predictions.

As these examples illustrate, the structure of a plant community will likely have a strong influence on the evolution of plant defenses. The selective impact on defense can be both qualitative and quantitative in nature. For example, plant community composition can change the level of defense that is favored either by altering the strength of an interaction or the expression of defense costs. Vegetation heterogeneity can also alter the actual types of defenses that are favored in a focal plant species, as predicted by apparency theory. Similarly, Lau's work suggests that tolerance may be selected in the presence of one species (Medicago), while increasing resistance may be favored when that species is absent from the neighborhood. Such findings suggest that vegetation heterogeneity could be a strong force in maintaining variation in both the type and level of plant defense in natural plant populations. While relatively few studies have investigated this possibility, we suspect it may be a common phenomenon. In particular, it would be instructive to determine the scale at which vegetation heterogeneity influences these evolutionary responses and to further investigate the mechanisms underly- 
ing the empirical patterns. For example, in Lau's work, the type of defense that is favored may shift because: (1) the presence of Medicago alters the costs of tolerance and resistance in different ways; (2) the existence of genetic correlations between defense traits and other ecologically relevant traits, such as competitive ability; or (3) the relative benefits of the different defense strategies depend on the presence and abundance of alternate hosts.

\section{The Plant Community's Role in the Evolution of Insect Traits}

The microevolution of herbivore strategies and, in particular, how this process is altered by plant community structure has been relatively little studied compared to the evolution of plant defense. Although tradeoffs in fitness on alternate host plants has been the primary focus of studies on specialization of herbivores, when the plant neighborhood is considered, other possibilities emerge (see Tables 1 and 2). For example, local specialization by generalist species, where one population tends to feed on one host plant while another population in a different location feeds primarily on an alternate host plant, has long been reported, and such effects are likely the result of variation in plant community structure (Fox and Morrow 1981). Additionally, plant diversity may alter host choice and use as well as availability of enemyfree space for herbivores. Finally, plant neighbors may also affect the evolutionary response of herbivores to changes in host plant defenses. Below we outline several different possibilities of how plant complexity influences selection on herbivores, progress to date, and methodological suggestions.

\section{ECOLOGICAL OPPORTUNITY}

The key concept for how the plant community may influence insect evolution is "ecological opportunity" (Strong et al. 1984) (Figure 2), or how the presence of other plant species in the neighborhood provides an opportunity for both host shifts and diet expansion. Whether these opportunities are realized depends on multiple factors, such as chemical similarity and genetic and physio-

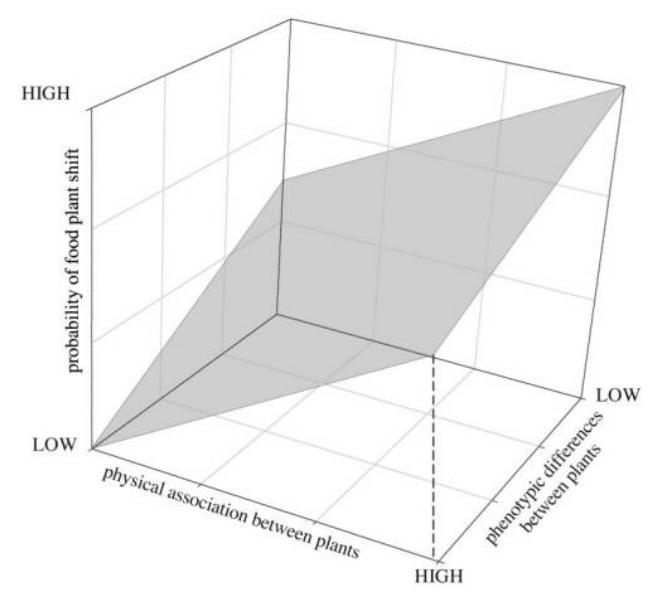

Figure 2. Predicting Host Shifts

Conceptual model of how phenotypic differences and physical association (or ecological opportunity) between plants affect the likelihood of specialist herbivores host-shifting between those plants. Host shifts are most likely between plants that are phenotypically similar and that are consistently in close physical and phenological association. Additional ecological opportunity arises from the novel host being of high food quality, abundant in the nearby environment, or a habitat that is relatively free of enemies. (Modified from Mooney 2003).

logical constraints (Bernays 2001). When examining phylogenies of closely related insect herbivores, two patterns emerge: host shifts occur onto either taxonomically related species (Becerra 1997; Janz and Nylin 1998; Murphy 2004) or species within the same habitat (Pappers et al. 2002a,b). For example, herbivores of parasitic plants often have close relatives that feed on the hosts of parasitic plants (Anderson 1970; Mooney 2003). Although parasitic plants are usually taxonomically quite distant from their hosts, they often share chemical defense similarity (Adler 2000); therefore, host shifts may be facilitated by both a shared chemistry and ecological opportunity. The reason why some lineages mainly proliferate on taxonomically related plants while others shift to taxonomically unrelated plants is still unclear, but it is likely due to both the propensity for egg-laying mistakes by females and to physiological constraints during feeding. For instance, the leaf beetle genus Galerucella has been shown to use taxonomically distant plants within the 
same or nearby habitats (e.g., Pappers et al. 2002b), and this may be related to their inability to use long distance odor cues for host finding (Hambäck et al. 2003), which increases the probability of females landing on nonhost plant species (Wiklund 1984).

The ability of an insect herbivore to hostshift depends on whether its population contains sufficient genetic variation, which may be linked to the diversity (and opportunity) of the plant community. For example, it has been generally predicted that herbivore populations experiencing a diverse host plant community will retain a greater reservoir of genetic variability than herbivore populations on single host plant species (Hawthorne 1997). If true, then herbivores from diverse plant populations may show a greater ability or rapidity in adapting to new host plants. The single test of these hypotheses, however, found no difference in the ability of the dipteran leafminer (Liriomyza trifolii) to adapt to novel hosts when replicate populations were maintained for 20 generations in mixed versus single host plant arenas (Hawthorne 1997).

While host shifts necessitate that an insect is able to use the novel host as a resource, extending the resource base may not be the primary fitness benefit from the host shift. Several studies suggest that an ecological opportunity for enemy-free space on an alternate host plant may outweigh a fitness cost of reduced host plant quality (Bernays and Graham 1988). Two recent studies describe an apparent host shift of relatively specialized herbivores onto plants taxonomically unrelated to the primary hosts (Mira and Bernays 2002; Murphy 2004). The important result of these studies is that in the presence of predators, larval fitness is greater on the novel hosts than on the ancestral host; but, in the absence of predators, larval fitness is greater on the ancestral host. It is unclear whether such enemy-free space mediated hosts shifts are more likely to occur in diverse compared to less diverse plant communities, although this prediction stems from our discussion of ecological opportunity. In addition, the ecological opportunity for enemy-free space may be particularly large when host shifts involve taxonomically unrelated plants, as this would cause a larger mismatch between herbivore and host plant odor cues. For example, this mismatch could particularly cause problems for parasitoid species that use specific induced plant volatiles for locating herbivore host species (Vet and Dicke 1992).

Finally, the ecological opportunity afforded by diverse plant communities extends to benefits of a diet mixing strategy. Some herbivores, including several Arctiid moth caterpillars, are so-called toxic plant generalists. Individuals of such species typically feed on several plant species over the course of their lifetime, including hosts that are apparently quite noxious. Several hypotheses have been put forth for why such apparent suboptimal choices are made (Singer 2001; Singer et al. 2002; Singer and Stireman 2003). After rejecting alternative hypotheses, Michael S Singer and colleagues have recently discovered that caterpillars of Grammia geneura sacrifice high growth by choosing a mixed diet that includes toxic plants, but that this strategy increased resistance against parasitoids (Singer et al. 2004). Thus, although generalist herbivores may find nutritionally adequate (or even superior) resources in less diverse host plant stands, there may be underappreciated tritrophic benefits of diet mixing which can only be realized in diverse host communities.

\section{HOST PLANT ABUNDANCE}

The probability of taking advantage of ecological opportunity will naturally increase both with a diversity of options and with the relative abundance of nonhost plants. While host shifts and diet expansions are possible when novel hosts are rare, they are likely to be more common when nonhost plants are abundant, thus providing substantial ecological opportunity. These possibilities have been extensively studied by Michael C Singer and colleagues on Euphydryas editha butterflies. Singer (1971) showed that oviposition preferences differed among conspecific butterfly populations, and suggested that these preferences might interact with the relative abundance of potential host plants to generate patterns of host use. Later work demonstrated this through extensive surveys and experiments of numerous butterfly populations. At one site, a plant 
species that was not the most preferred by any insect (in choice tests) received $80 \%$ of the eggs, presumably because it was abundant and the preferred plant was rare (Singer et al. 1989). At a second site, a plant species preferred over all others by $25 \%$ of the butterflies received only $5 \%$ of the eggs in the field, presumably because of its rarity (Singer 1983). Examples in which the most abundant local host is not the preferred host suggest that variation among sites in relative density of the various hosts is not the only factor tied to variation in host preference (Singer and Wee 2005).

In this system, the importance of variable plant abundance among sites is that it combines with genetic variation of both insect preference and plant resistance to generate spatial variation in the pattern of plant-insect associations (Singer and Parmesan 1993). Plant abundance is apparently less important than plant quality to the evolution of insect preferences, but plant abundance interacts strongly with those evolved preferences to produce observed patterns of egg deposition and host use. Perhaps the strongest pattern for E. editha is that wherever the host plant Collinsia torreyi occurs in large persistent patches suitable for the complete butterfly lifecycle, the butterfly is locally adapted to have this as the preferred host (irrespective of density). If this host is not sufficiently longlived at a site, however, then the insects lay eggs on another host to which they then become adapted, and essentially ignore $C$. torreyi.

Where human activities have altered the relative quality of available hosts, rapid evolution of preference and diet has also ensued. In one case, this alteration was the invasion of an exotic host plant Plantago lanceolata (Thomas et al. 1987; Singer et al. 1993). Although larvae from communities with and without Plantago grew equally well on this novel plant, adult acceptability of Plantago has only evolved in populations with the novel host. In a second case, logging caused a change in environment that rendered an abundant and suitable host phenologically available to the insects (Singer et al. 1993; Boughton 1999). This environmental change resulted in genetic changes in the butterfly population that increased preference for the novel host. Quite amazingly, in many of these populations where host shifts have occurred, preference for the original host has been evolutionarily lost or severely reduced. Thus, human-induced activities that have altered plant community composition have created ecological opportunity for host shifts and evolutionary responses in insects.

Because host plant abundance changes over time, so do ecological opportunities, and this may cause temporal dynamics in host shifts. This was discussed in the 1970s in relation to the plant defense guild hypothesis, because such temporal changes may have reciprocal effects on plant defense evolution. Peter Dolinger et al. (1973) suggested that a Lycaenid butterfly (Glaucopsyche lygdamus), which utilizes six potential local hosts in Colorado (all legumes), was prevented from specializing on any one due to frequency dependent selection (Figure 3). As any one plant species evolved defenses, escaped herbivory, and became the dominant plant, selection would favor the evolution of preference and counter adaptations by the herbivore for that plant, and thus the dominant plant would eventually be suppressed by herbivory. There would typically be a lag time in the subsequent herbivore response; the herbivores would still prefer the previously dominant species even though a different species is now dominant (and represents ecological opportunity in terms of an underused food source). Ultimately, we expect that the herbivore will be selected for increased preference and performance on this new abundant host (Figure 3). This evolutionary cycle of plant escape and subsequent resource concentration would be countered by adaptation and short-term specialization by the herbivores. Nonetheless, long-term dynamics predict the maintenance of plant species diversity and reduced species-level specialization in the insect. Frances Chew (1979) advanced a similar idea for the coevolutionary interaction between Pierid butterflies and their Brassicaceous host plants; in communities with multiple potential hosts, butterflies may show local adaptation to one plant depending on the relative abundance of others. 


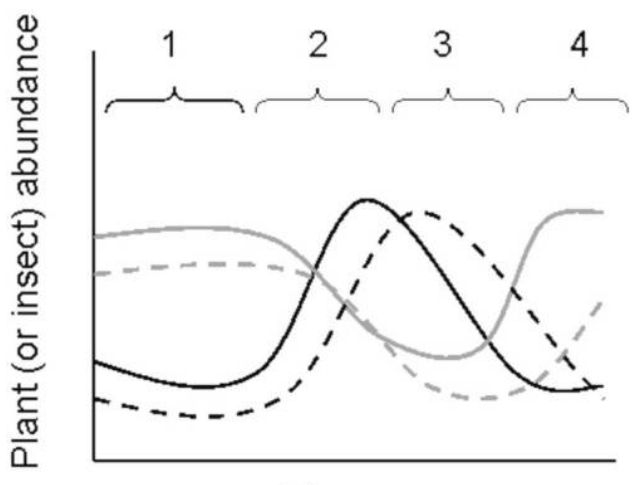

Time

Figure 3. Frequency Dependence in MultiSpecies Coevolution

Conceptual model of the frequency dependent selection that promotes the maintenance of both plant and insect diversity, as suggested by the Plant Defense Guild Hypothesis (Atstatt and O'Dowd 1976). The solid black line represents the abundance of plant species A. Initially, when A is rare there are few herbivores that prefer to feed on it (1); however, as A becomes relatively more abundant, the number of herbivores that prefer to feed on plant species A (dashed black line) increases (2). As the frequency of herbivore genotypes that feed on A increases, they decrease the population growth rate of $\mathrm{A}$, allowing competing plant species B (gray line) to increase in abundance (3). Again, after a time delay, the number of herbivore genotypes that prefer to feed on B (dashed gray line) begins to increase, due to selection on the insect herbivores to preferentially feed on the most abundant host plant (4). This frequency dependent selection produces stable cycles of alternating plant (and herbivore) abundance.

\section{HOST-ALTERNATION STRATEGIES}

An extreme example of how ecological opportunity and plant community interactions may shape the evolution of insect life histories is the host-alternation strategy. The herbivores are quite specialized, but usually require two taxonomically and phenotypically different hosts at different times of the season (often woody host plants during spring and herbaceous plants during summer). Host alternation is restricted to $10 \%$ of the some 4,000 species of aphids, and has also been reported from other hemiptera (e.g., leaf hoppers and membracids) (Moran 1992) and a couple of diptera (Cook et al. 2002; Yukawa et al. 2003). Although there are many hypotheses for the evolution of such complex life cycles, the dominant idea focuses on the maximization of fitness on host plants, where plant quality (and potentially enemy-free space) radically changes seasonally (Moran 1992).

Anthony Dixon and Ranajit Kundu (1994) have further proposed that the evolution of host alternation is dependent on herbivores living in diverse plant communities. As evidence, they report that few $(6 \%)$ aphids on "dominant" tree hosts in Britain are hostalternating; conversely, over half $(58 \%)$ of the aphids on "subdominant" trees are hostalternating. Dixon and Kundu speculate that climax woodland communities, composed of one or a few dominant species, provide little ecological opportunity for the evolution of host alternation.

Host alternation also has ecological and evolutionary implications for the plant species involved. Because both plant species are required for the persistence of an insect population, herbivore attack rates on one host plant are likely tightly linked to those on the other. If, for example, one host plant is very abundant, it may boost herbivore population growth rates, thereby increasing damage on the second host plant. Similarly, one can imagine that the two host plants are also tightly linked evolutionarily, albeit indirectly. If one host plant is highly resistant to the herbivore, it may depress herbivore population growth rates, thus decreasing damage levels on the second host. This second plant would then be released from intense herbivore pressure and may be under selection for reduced defense levels. Thus, the effects of one host on the other may not depend only on presence and abundance, but also on its level of defense. While strong indirect effects between plant species mediated by hostalternating herbivores seem plausible, we are aware of only one study observing such interactions. Carsten Thies et al. (2005) reported that densities of Rhopalosiphum padi aphids on cereals were positively correlated with the proportion of neighboring noncrop areas with Prunus padus (the winter host for the aphid). 


\section{NEURAL CONSTRAINTS HYPOTHESIS}

According to Elizabeth Bernays's Neural Constraints hypothesis, diverse plant communities make host choice problematic for herbivores, thereby imposing selection for specialization (Bernays 2001). Although more choices in diverse habitats may result in ecological opportunity for host shifts, in the short term such plant diversity is suggested to impose a greater strain on neural processing, causing either inefficient decision making (exposing organisms to predation or other risks) or poor quality decision making (choosing plants on which the herbivore has low fitness). Despite limited direct support for more diverse plant communities imposing a different shape or strength of selection on herbivores compared to less diverse communities, circumstantial evidence from mesocosm experiments is suggestive. Bernays (1999) reported that the whitefly (Bemisia tabaci) had lower performance in mixtures of host plants compared to when with only the best of the hosts; observations demonstrated that in mixtures whiteflies moved more and switched between plants more frequently compared to when with single plant species. The Neural Constraints hypothesis suggests that patterns, such as the level of specialization, should vary with community diversity. Although these patterns have not been investigated, examination of host races of herbivores from agricultural versus natural populations would provide an excellent test. Specifically, if agricultural populations (i.e., evolving in low diversity habitats) remain behavioral generalists while natural populations (i.e., evolving in higher diversity habitats) are more specialized, then this would be consistent with the Neural Constraints hypothesis driving specialization. These somewhat counterintuitive predictions for choice and host-use type experiments would need to be followed up with behavioral, physiological, and fitness assays (Bernays 2001). In particular, the Neural Constraints hypothesis makes these predictions about specialization for preference as mechanisms to avoid ecological pitfalls, as opposed to traditional perspectives on specialization that focus on physiological adaptations to plant defenses.

\section{EFFECTS OF PLANT HETEROGENEITY ON INSECT COUNTERADAPTATION}

While the effects of the surrounding plant community on diet choice have received the most attention, plant community heterogeneity can also interact with insect demography to influence the rates of insect counteradaptation to plant defenses. In this scenario, the level of variation in the magnitude or type of plant defense (either interspecific or intraspecific variation) interacts with insect demography to influence the intensity of selection on herbivore offensive strategies. This occurs because resistant plant genotypes successfully depress insect population growth rates, while susceptible genotypes serve as reservoirs for insect population growth. Because the vast majority of insect population growth occurs on susceptible genotypes, and because insect traits that permit feeding on resistant genotypes can be costly, insect counteradaptation to resistant plant genotypes may be overwhelmed by the demographic vigor and competitive advantage of insect populations.

While this phenomenon has been documented in agricultural systems and is commonly applied to extend the lifespan of resistant crop cultivars (Gould 2003), it may be rare in natural ecosystems. Because plants can also evolve in natural systems, one might expect susceptible genotypes to be selected against and to continually decrease in frequency, thereby eliminating the susceptible refuges. If another selective force can maintain low, but stable, frequencies of susceptible genotypes, however, then this mechanism could occur in natural ecosystems as well. Such a case may be especially likely when the variation in susceptible versus resistant genotypes is interspecific in nature and the susceptible species cannot be competitively excluded from the community (Figure 3), or if external environmental forces alter the relative attractiveness of various host plants, as suggested by Atsatt and O'Dowd (1976). Intraspecific cases in which (1) tolerance and resistance are mutually exclusive defense strategies and strongly negatively correlated (Fineblum and Rausher 1995) or (2) there is genetic variation in the strength of induced defenses (Gardner and Agrawal 2002) could also possibly slow the evolution of insect offensive strategies. 
The above examples document effects of plant community variation on the evolution of host preference or performance. However, evolutionary responses in other traits could also occur. For example, if vegetation heterogeneity influences predation rates on the herbivores, one might expect to observe altered selection on antipredator behaviors of the herbivores. Vegetation heterogeneity may also affect selection on traits such as dispersal ability and life-history characters (Carroll et al. 2003). Thus, the microevolutionary dynamics between plants and herbivores, and the evolution of a wide variety of both plant and herbivore traits, may be predictably shaped by plant community characteristics.

\section{Macroevolutionary Consequences of Plant Community Heterogeneity}

Most of the examples we cite are tests of the hypothesis that selection on plant defense or insect feeding behavior is diffuse. Each of the plant examples in this paper illustrates that selection imposed on a plant by an herbivore is not independent of the presence of other community members. This diffuse selection may generate variation in the apparent adaptations that plants have to herbivores and vice versa. In fact, this level of variation in interactions was surmised 25 years ago, and the result was a general prediction that the local community members will influence selection on plant defense and host-plant specialization by herbivores, and that interactions may be highly geographically variable (Fox and Morrow 1981). These basic predictions imply that geographic variation in community composition will likely result in geographic variation in species interactions. Thus, variation in community composition derived from both stochastic processes and abiotic environmental conditions may play a role in promoting the genetic differentiation and local adaptation that are the first steps to speciation.

\section{GEOGRAPHIC MOSAICS}

Further work on the idea that community composition (and, therefore, species interactions) is geographically variable has led tothe formulation of the concept of geographic mosaic coevolution (Thompson 1988, 1994, 1999). John Thompson argues that geographic variation in the intensity of the plantherbivore association interacts with patterns of gene flow to produce evolutionary "hotspots" (where the plant-herbivore interaction is a tightly coevolved dynamic) and evolutionary "coldspots" (where the plant traits and herbivore traits are mismatched and not tightly coevolved). While Thompson has criticized diffuse coevolution as a catchall phrase that trivializes coevolutionary processes (Thompson 1988, 1994, 1999), it seems apparent that diffuse selection can be a mechanism that generates geographic variation in the interactions between species. This realization suggests that the concepts of diffuse selection and geographic mosaics are indeed compatible.

As a preliminary example of how diffuse selection may generate geographic variation in plant-herbivore coevolution, Art Zangerl and May Berenbaum (2003) have demonstrated that the plant defensive phenotype of wild parsnip (Pastinaca sativa) matches the detoxification abilities of the parsnip webworm (Depressaria pastinacella) in 12 of 20 populations studied across Illinois and Wisconsin. This matching is suggestive of reciprocal adaptation. In four populations, an alternative host, cow parsnip (Heracleum lanatum), was present, and in each of these populations there was a "mismatch" between the level of plant defense and insect counterdefense. Although these four populations with an alternate host were not spatially independent (they are regionally clustered), the authors argue that the presence of the alternate host may disrupt reciprocal selection between the wild parsnip and the webworm. If this is the case, then plant community members are acting as agents of diffuse selection, which results in a pattern of geographic variation in the coevolutionary interaction between two species. A definitive test would involve a reciprocal transplant study to assess whether differential local selection has, in fact, occurred.

\section{LOCAL ADAPTATION AND SPECIATION}

Because vegetation heterogeneity can cause spatial variation in plant-herbivore in- 
teractions and variation in species traits, this heterogeneity could promote genetic differentiation and adaptation to local environmental conditions. If selection is strong enough or if gene flow is disrupted for long enough to promote reproductive isolation, then this vegetation heterogeneity, and the resulting genetic differentiation, could result in speciation. For example, we might expect vegetation heterogeneity to promote speciation in insects because different herbivore populations may become locally adapted to different host plants, as suggested by the concept of geographic mosaics. Populations of a walking-stick insect (Timema cristinae) that use different host-plant species have evolutionarily diverged in several traits including host preference (Nosil et al. 2002); divergent selection for host adaptation has apparently led to the repeated evolution of reproductively isolated populations in this species. Several of the best examples of recent speciation events involve insects feeding on different host plants, where speciation (or at least hostrace formation) resulted from a host shift onto an alternate host that is a common community member (Bush 1994; Nason et al. 2002; Via and Hawthorne 2002; Stireman et al. 2006).

In other cases, expansion to novel host plants has occurred, followed by adaptive changes in feeding traits. For example, over the past 50 years, soapberry bugs have taken advantage of ecological opportunity and colonized several exotic plant species as novel hosts (Carroll and Boyd 1992). The soapberry bugs feeding on novel hosts have diverged with respect to beak length, a trait that influences feeding ability on the different food sources. Populations that have colonized introduced plants with smaller fruits than the original host have evolved shorter beaks, while those that have colonized introduced species with larger fruits have evolved longer beaks. Although there is no current evidence that the host races are reproductively isolated, populations on the different host plants are locally adapted to their plants and rarely interbreed because of large distances between host plant populations (Carroll et al. 1997, 1998). Thus, the soapberry bugs may be in the earliest stages of speciation, and the populations on different hosts may represent potential incipient species. A similar case has been argued within the Galerucella nymphaea complex (Nokkala and Nokkala 1998). Within this species complex, individuals feeding on marsh species such as Comarum palustre may breed in the laboratory with individuals collected from water lilies (Nuphar and Nymphaea). Interbreeding rarely occurs in the field, however, and hybrid larvae have reduced survival because of apparent larval adaptations for feeding on aquatic versus marsh plants.

\section{MACROEVOLUTION AND THE ESCAPE AND RADIATE MODEL}

In an attempt to explain the diversification of plants and butterflies, Paul Ehrlich and Peter Raven (1964) proposed a model that strongly links the microevolutionary processes discussed above to macroevolutionary patterns. Their Escape and Radiate model of coevolution hypothesized that the evolutionary innovation of a defense in plants results in freedom from attack, and this freedom causes adaptive radiation of the plant lineage. Similarly, they argued that the evolution of a novel offensive trait (or counteradaptations to plant defenses) will allow unencumbered exploitation of plants (Karban and Agrawal 2002), and ultimately adaptive radiation of herbivore lineages onto a set of closely related plants. Despite the broad appeal of this hypothesis and its lasting impact, the logical link between escape of plants from herbivory and speciation is still unclear. The hypothesis is that reduced herbivory allows for larger plant populations to colonize new habitats and be less prone to extinction, and for greater genetic variation available for selection. The latter point is especially important as constraints associated with adaptation (i.e., negative pleiotropy) to one selective agent may limit the ability of plants to adapt to other novel environments. If large persistent populations with high genetic variability are more likely to undergo adaptive radiation than smaller populations with constrained genetic variability, the Escape and Radiate model may be reflected in nature.

As far as the macroevolutionary patterns are concerned, there is some evidence that 
novel plant defenses are indeed associated with diversification. For example, Brian Farrell et al. (1991) report that plant taxa with defensive latex or resin canals (e.g., Dussourd and Eisner 1987) are more speciose than sister taxa that lack these defenses; this pattern was consistent in 13 of 16 paired lineage comparisons. The reciprocal logic of adaptive radiation in herbivores following from the evolution of counteradaptations is strongly supported by the pattern that closely related insect species tend to consume closely related plant species (Ehrlich and Raven 1964; Strong et al. 1984). Although the specific offensive tactics that allow these radiations are poorly understood, the pattern has been found for diverse groups of butterflies ( Janz and Nylin 1998) and specific lineages of beetles (Becerra 1997). The likely radiation of herbivore lineages onto closely related plant species will depend, at least in part, on the ecological opportunity for the herbivores. In other words, at least at a regional scale, there must be related host plants available for colonization.

In some cases, the colonization and radiation will occur irrespective of the relatedness of host plants available in the vegetation community. For example, after bananas invaded the Hawaiian Islands some 1000 years ago, a species of Hedylepta moths adopted them as a host plant (Zimmerman 1960). The moths then radiated, and at least five species fed on various introduced hosts (Zimmerman 1960). Elwood Zimmerman speculated that this host shift and subsequent radiation resulted, in part, from changes in the plant community: native host plants declining in abundance due to human activity and being replaced by bananas and coconuts.

\section{Future Directions}

While the empirical study of the evolutionary consequences of plant community composition is just beginning, the accumulating observational and experimental evidence suggests that vegetation heterogeneity can be important not only to interactions among plants, but also to interactions between plants and their enemies. We outline emerging areas of research on how plant community het- erogeneity may shape the evolution of plantherbivore interactions.

\section{INTERDEPENDENCY OF PLANT} AND INSECT DIVERSITY

We believe that more work linking broad patterns of plant diversity with insect diversity and attack rates is one of the first steps to discover the ecological effects (and potential evolutionary outcomes) of variation in plant diversity. Observational (Murdoch et al. 1972; Hawkins and Porter 2003) and experimental (Siemann et al. 1998; Knops et al. 1999) studies have demonstrated a positive relationship between plant species richness in communities and total arthropod species richness. Similar work has recently been reported from intraspecific genetic diversity in plant populations (Wimp et al. 2004; Johnson et al. 2006). The work by Marc Johnson et al. (2006), in particular, demonstrates experimentally that fine-scale intraspecific genetic diversity in plant patches generates enough phenotypic variability to shape arthropod communities. This work is unique in identifying a potential coevolutionary feedback between plant genetic diversity, enemy attack, and plant fitness. Thus, when plant diversity (at any scale) shapes the herbivore community, and the herbivores are important selective agents on the plant community, there is strong potential for community-wide feedbacks.

The interplay between plant diversity, insect diversity, and herbivore attack rates is a complex and important area of research. While there tends to be a positive correlation between plant diversity and insect diversity, there tends to be a negative relationship between plant diversity and levels of herbivore damage on focal plant species. These contrasting patterns likely result from a disconnection between insect diversity and abundance that may be caused by either a greater abundance of predators in diverse habitats (Enemies Hypothesis) or to decreased herbivore population growth rates and higher emigration rates from diverse habitats (Resource Concentration Hypothesis) (Root 1973). Additionally, the host range of herbivores (Andow 1991), search modality (Hambäck and Beckerman 2003; Hambäck et al. 
2003; Bukovinszky et al. 2005), and the possibility for positive feedback systems (Turchin 1989; Hambäck and Englund 2005) may provide other predictive axes. First, reduced attack rates in diverse habitats are always predicted when the higher diversity does not provide additional food sources. This effect may be particularly strong for species, such as many generalist herbivores, that do not use long-distance cues for identifying host plants. Second, increasing plant diversity is predicted to affect visually searching herbivores more than species using odor cues because odor cues are less distorted in complex habitats. Third, positive feedback systems, such as attraction to already damaged plants, may amplify small differences in attack rate between plants in simple and diverse habitats (Hambäck et al. 2003) that have arisen for other reasons. One reason for this is that if the first herbivores that arrive on plants have a slightly higher probability of landing on plants in simple habitats, these plants would then function as magnets for later arriving herbivores (Turchin 1989).

Several examples also exist where focal plant species receive more herbivory in high compared to low diversity plots (Prieur-Richard et al. 2002). In these cases, the mechanisms linking plant diversity and insect diversity may also explain the patterns between plant diversity and herbivore attack; the focal plant species may receive more herbivory simply because an important herbivore is more likely to occur in diverse plant communities (Figure 1). This may result because of plant diversity (i.e., more resources), but could also result from other mechanisms. For example, an alternate host plant species that causes associational susceptibility for the focal plant may be more likely to occur in a high diversity environment (Prieur-Richard et al. 2002; Aquilino et al. 2005). While the effects of plant diversity are difficult to separate from those of plant community composition, several experimental designs have been proposed to differentiate between these confounding effects (Loreau and Hector 2001; Mulder et al. 2001). Johnson et al. (2006) have modified these methods to allow for tests of plant di- versity on insect diversity that are somewhat more complicated than effects on productivity and involve iterative resampling from a subset of the data to create expected datasets, which can be compared to the observed data.

The examination of underlying mechanisms in these examples suggests that all consequences of plant diversity may not be equal. Some mechanisms, such as olfactory interference, are likely to be connected to quite specific plant species, while other mechanisms, such as visual interference, may depend on general plant characteristics (Hambäck and Beckermann 2003). Correct identification of underlying mechanisms is therefore pivotal for understanding the role of vegetation heterogeneity in modifying plant-herbivore evolution.

\section{SCALE DEPENDENT CONSEQUENCES OF PLANT DIVERSITY}

Effects of vegetation heterogeneity likely vary greatly depending on spatial scale. A recent meta-analysis illustrates this phenomenon; Riccardo Bommarco and John Banks (2003) found that experiments investigating the relationship between plant diversity and herbivore abundance were more likely to detect a negative correlation when treatment plots were small (less than $16 \mathrm{~m}^{2}$ ) compared to when plots were larger. The underlying mechanism is likely that selection behavior by herbivores is most strongly expressed at small spatial scales. For instance, fine-scale variation in vegetation heterogeneity may have large impacts on herbivore host use because herbivores can move across patches allowing for greater opportunity to choose appropriate host plants and communities (Bommarco and Banks 2003). In contrast, at larger spatial scales, insect herbivores may be unable to select among host plants because of limited knowledge or low dispersal ability. In large patches, this has the consequence that differences among monospecific and mixed plots is strongest at the border between these areas. For instance, studies on turnip root flies (Delia floralis) indicate that the egg-laying rate on border plants in monocultures is nearly $200 \%$ higher than neighboring plants in polycultures; egg-laying rates on plants at the center of 
the same monoculture plots is only $70 \%$ higher than on center plants in the polycultures (Björkman, Rämert, and Hambäck unpublished data). This scale-dependent pattern occurs because of the movement behavior expressed by females when encountering unsuitable host plants.

In addition to the scale-dependencies involved in herbivore selection behavior, differences between small and large plots may also be caused by differences in the importance of herbivore selection behavior versus local growth (Hambäck and Beckerman 2003). While patterns at small spatial scales may be driven by insect preference, patterns at larger spatial scales, where patch choice is not an option, may be driven by insect performance. Accordingly, experiments performed at small spatial scales may only be able to detect the short-term dynamics that result from emigration and immigration and individual choice in patch use. In contrast, experiments performed at large spatial scales may be able to detect the longer-term dynamics that result from differential insect population growth rates, but may be less able to detect shortterm dynamics. In all cases, the relevant scale of investigation depends on both the level of heterogeneity in the plant community and the dispersal ability of the insects. For example, Koricheva et al. (2000) report that only the most sessile insects responded to smallscale plant diversity manipulations.

Scale is also relevant to the effects of vegetation heterogeneity on insect evolution and diversification. For example, gene flow between insect populations on different hosts may be much less when the varies over larger spatial scales than when plant community varies over larger spatial scales than when variation is fine-scale in nature. Thus, variation over larger spatial scales may promote the divergence between insect populations that is the first step toward reproductive isolation and speciation. In contrast, however, variation at intermediate scales may increase the speed of speciation due to reinforcement, though this remains controversial (Servedio and Noor 2003). In short, both the underlying mechanisms and the actual patterns observed may differ depending on spatial scale. Consequently, the scale at which heteroge- neity occurs should be an important consideration for studies investigating relationships between plant community dynamics and herbivore communities.

\section{VEGETATION HETEROGENEITY AND} GENETIC VARIABILITY

Recent studies have illustrated that plant community diversity tends to be positively correlated with intraspecific genetic variability (Vellend and Geber 2005). It is currently unclear as to whether this correlation results from a causal process (i.e., community diversity increasing genetic diversity or vice versa) or whether similar mechanisms drive diversity patterns at both interspecific and intraspecific levels (Vellend and Geber 2005). However, if vegetational heterogeneity does causally impact intraspecific genetic variation, then it may be another mechanism by which plant community composition influences the evolution of plant-herbivore interactions. For example, many studies have demonstrated that intraspecific variation alone can influence herbivory rates (Fritz and Simms 1992). Furthermore, work by Johnson et al. (2006) illustrates that the influence of plant intraspecific genetic variation on herbivore community dynamics may even feed back to affect the plant community. The missing link in this process is determining whether vegetation heterogeneity is a driving force that causally impacts intraspecific diversity. Ultimately, factorial experiments in which both intraspecific diversity and interspecific diversity are manipulated are needed to ascertain the causality of these relationships and how the two levels of diversity independently, and interactively, influence plant-herbivore dynamics. As an initial step, Boothe and Grime (2003) have demonstrated that plant species diversity is more likely to be maintained in genetically diverse plots compared to genetically uniform ones. Theory predicts a similar relationship (Vellend 2006). The consequences of this dynamic for relationships with herbivores represent an open avenue for research.

\section{PLANT DEFENSE VARIATION IN DIFFERENT COMMUNITY TYPES}

In addition to quantitative genetic studies to investigate microevolutionary patterns, obser- 
vational studies of defense traits in communities of differing composition can potentially provide evidence for evolutionary responses. While caution must be exercised since, without manipulative experiments, one cannot be certain whether vegetation heterogeneity is the mechanism responsible for any observed differences, we find work that links geographic variation in defense levels with variation in plant community composition (e.g., Zangerl and Berenbaum 2003) highly suggestive and enticing. Future studies should examine the defense phenotypes of plants in multiple community types and consider reciprocal transplant experiments to identify the probable selective agents responsible for variation in levels of defense.

\section{PLANT INVASIONS AND COMMUNITY HETEROGENEITY}

Situations in which community composition is being inadvertently manipulated over broad geographic scales, such as by changes in agricultural practices or by biological invasion, provide excellent opportunities to monitor evolutionary changes in insects and their host plants. For example, Chew (1979) speculated that the selective pressures on the Brassicaceous host plants she studied would likely differ following invasion by the exotic crucifer Thlaspi. Several other examples of invasive plants that apparently alter attack on natives have recently emerged (Zimmerman 1960; Thomas et al. 1987; Carroll and Boyd 1992; Solarz and Newman 1996; Rand and Louda 2004; Lau and Strauss 2005; Russell and Louda 2005; Lau 2006). We believe that the study of plant-herbivore interactions in both invaded versus non-invaded sites and in introduced versus native habitats are "natural experiments" that provide interesting research opportunities. For example, Darwin and others have suggested that among introduced plants, those lacking native congeners should be the most likely to flourish because of the lack of very similar competitors (Darwin 1859; Rejmánek 1999; Daehler 2001). This hypothesis can be extended to the effects of phylogenetic relatedness on plantherbivore interactions. Because native and in- troduced congeners are not only likely to share similarities in resource use, but in chemical and physical defenses as well, they are likely to be attacked by common consumers (Connor et al. 1980). We predict that in communities with native congeners, host shifts by native herbivores onto introduced plants are more likely than in communities without native congeners. Evidence that native herbivores frequently host-shift onto introduced plants is accumulating (Connor et al. 1980; Agrawal et al. 2005), although whether such host shifts are associated with the presence of congeneric neighbors remains to be determined.

Plant diversity, in general, is also often associated with invasion resistance. This is typically thought to occur because a more diverse community implies that a greater percentage of available resources are already being used, leaving little empty niche space for an exotic plant to invade. However, insect herbivores could also contribute to this pattern. If insect diversity is greater in high diversity plant communities, then the probability of a host shift onto the colonizing exotic may be more likely, thus limiting its invasion success. The first study to address this hypothesis demonstrated that plant diversity increased herbivory on a colonizing exotic species, and that this increased herbivory resulted in decreased demographic vigor of the exotic (Prieur-Richard et al. 2002). Furthermore, these results were driven by functional group composition, and the presence of one unrelated family contributed most to the increased herbivory observed in high compared to low diversity plots, rather than the presence of closely related confamilials. A broad survey investigating herbivory on noninvasive exotic species versus highly-invasive exotics could shed light on whether host shifts by native (or introduced) herbivores can influence the invasion potential of exotic plants, and whether the composition of the plant community influences this process. The only study to attempt to link herbivore host shifts with invasiveness confirms the first part of this prediction; highly invasive species received less herbivory than less invasive exotics (Carpenter and Cappuccino 2005). 


\section{Conclusions}

Given the myriad ways in which vegetational heterogeneity can influence the ecology of plant-herbivore interactions, the evolutionary effects of such heterogeneity are also likely pervasive. Indeed, much of what we have reviewed indicates not only strong effects of plant community heterogeneity on herbivores, but also provides feedbacks that reshape the plant community. While studies involving multiple interactors rapidly become cumbersome and difficult to manipulate, particularly when combined with the large sample sizes necessary for traditional quantitative genetic studies, observations and experiments at several scales can help to illuminate important patterns. Existing evidence suggests that competing plants alter selection (via various mechanisms) by herbivores on plant defenses. Likewise, host shifts, host race formation, and possibly speciation in herbivores are tied to plant community structure. These generalizations are no small victory for evolutionary ecology; they reject simple pairwise interactions as being all-important and have led to predictions for when and why host shifts are likely to occur. At least some of these evolutionary effects are mediated by tritrophic interactions, thus implicating an intertwining of variation in both the plant community and animal community interactions. Finally, we have outlined several open hypotheses (Tables 1 and 2), from the impact that vegetation heterogeneity has on the evolution of the host-alternation life-history strategy (and vice versa) to the importance of frequency dependent coevolutionary interactions. The reality of community ecology thus represents an important frontier for understanding the evolution of plant-insect interactions.

\section{ACKNOWLEDGMENTS}

We thank Marc Johnson, Marc Lajeunesse, Kailen Mooney, John Parker, Mike C Singer (University of Texas), Mike S Singer (Wesleyan University), and Christer Wiklund for providing helpful comments and discussion. Our research is supported by NSF DEB0447550 (AAA, www.herbivory.com), by NSF IBN0206601 (JAL and SY Strauss), and by the Swedish Research Council for Environment, Agricultural Sciences and Spatial Planning (FORMAS to PAH). JAL is currently supported by NSF IOB 0620318 to P Tiffin, R Shaw, and P Reich.

\section{REFERENCES}

Abrams P A. 1995. Implications of dynamically variable traits for identifying, classifying, and measuring direct and indirect effects in ecological communities. American Naturalist 146:112-134.

Adler L S. 2000. Alkaloid uptake increases fitness in a hemiparasitic plant via reduced herbivory and increased pollination. American Naturalist 156:92-99.

Agrawal A A. 1998. Induced responses to herbivory and increased plant performance. Science 279: 1201-1202.

Agrawal A A. 1999. Induced responses to herbivory in wild radish: effects on several herbivores and plant fitness. Ecology 80:1713-1723.

Agrawal A A. 2000. Benefits and costs of induced plant defense for Lepidium virginicum (Brassicaceae). Ecology 81:1804-1813.

Agrawal A A. 2001. Phenotypic plasticity in the interactions and evolution of species. Science 294:321-326.

Agrawal A A. 2004. Resistance and susceptibility of milkweed: competition, root herbivory, and plant genetic variation. Ecology 85:2118-2133.

Agrawal A A, Kotanen P M, Mitchell C E, Power A G, Godsoe W, Klironomos J. 2005. Enemy release? An experiment with congeneric plant pairs and diverse above- and belowground enemies. Ecology 86:2979-2989.

Agrawal A A, Kurashige N S. 2003. A role for isothiocyanates in plant resistance against the specialist herbivore Pieris rapae. Journal of Chemical Ecology 29:1403-415.

Anderson D M. 1970. Dodder weevils in simultaneous association with parasitic plants and their hosts. $\underline{\mathrm{Sci}}$ ence 168:132-133.

Andow D A. 1991. Vegetational diversity and arthropod population response. Annual Review of Entomology 36:561-586.

Aquilino K M, Cardinale B J, Ives A R. 2005. Reciprocal effects of host plant and natural enemy diversity on herbivore suppression: an empirical study of a model tritrophic system. Oikos 108:275-282.

Atsatt P R, O'Dowd D J. 1976. Plant defense guilds: many plants are functionally independent with respect to their herbivores. Science 193:24-29.

Augner M, Fagerström T, Tuomi J. 1991. Competition, defense and games between plants. Behavioral Ecology and Sociobiology 29:231-234. 
Becerra J X. 1997. Insects on plants: macroevolutionary chemical trends in host use. Science 276:253-256.

Bernays E A. 1999. When host choice is a problem for a generalist herbivore: experiments with the whitefly, Bemisia tabaci. Ecological Entomology 24:260-267.

Bernays E A. 2001. Neural limitations in phytophagous insects: implications for diet breadth and evolution of host affiliation. Annual Review of Entomology 46:703-727.

Bernays E, Graham M. 1988. On the evolution of host specificity in phytophagous arthropods. Ecology 69:886-892.

Bommarco R, Banks J E. 2003. Scale as modifier in vegetation diversity experiments: effects on herbivores and predators. Oikos 102:440-448.

Booth R E, Grime J P. 2003. Effects of genetic impoverishment on plant community diversity. Iournal of Ecology 91:721-730.

Boughton D A. 1999. Empirical evidence for complex source-sink dynamics with alternative states in a butterfly metapopulation. Ecology 80:2727-2739.

Bowers M D. 1991. Iridoid glycosides. Pages 297-325 in Herbivores: Their Interaction with Secondary Plant Metabolites, Second Edition, Volume I: The Chemical Participants, edited by G A Rosenthal and M R Berenbaum. San Diego (CA): Academic Press.

Brown B J, Ewel J J. 1987. Herbivory in complex and simple tropical successional ecosystems. Ecology 68:108-116.

Bukovinszky T, Potting R P J, Clough Y, van Lenteren J C, Vet L E M. 2005. The role of pre- and postalighting detection mechanisms in the responses to patch size by specialist herbivores. Oikos 109:435-446.

Bush G L. 1994. Sympatric speciation in animals: new wine in old bottles. Trends in Ecology and Evolution 9:285-288.

Callaway R M. 1995. Positive interactions among plants. Botanical Review 61:306-349.

Callaway R M, Kikodze D, Chiboshvili M, Khetsuriani L. 2005. Unpalatable plants protect neighbors from grazing and increase plant community diversity. Ecology 86:1856-1862.

Callaway R M, Pennings S C, Richards C L. 2003. Phenotypic plasticity and interactions among plants. Ecology 84:1115-1128.

Carpenter D, Cappuccino N. 2005. Herbivory, time since introduction and the invasiveness of exotic plants. Iournal of Ecology 93:315-321.

Carroll S P, Boyd C. 1992. Host race radiation in the soapberry bug: natural history with the history. Evolution 46:1052-1069.

Carroll S P, Dingle H, Klassen S P. 1997. Genetic differentiation of fitness-associated traits among rapidly evolving populations of the soapberry bug. Evolution 51:1182-1188.

Carroll S P, Klassen S P, Dingle H. 1998. Rapidly evolving adaptations to host ecology and nutrition in the soapberry bug. Evolutionary Ecology 12:955-968. Carroll S P, Marler M, Winchell R, Dingle H. 2003. Evolution of cryptic flight morph and life history differences during host race radiation in the soapberry bug, Jadera haematoloma Herrich-Schaeffer (Hemiptera: Rhopalidae). Annals of the Entomological Society of America 96:135-143.

Carson W P, Patrick J, Long Z T. 2004. A general rule for predicting when insects will have strong topdown effects on plant communities: on the relationship between insect outbreaks and host concentration. Pages 193-211 in Insects and Ecosystem Function, edited by W W Weisser and E Siemann. Berlin and New York: Springer-Verlag.

Chew F S. 1979. Community ecology and Pieris: Crucifer coevolution. Journal of the New York Entomological Society 87:128-134.

Cipollini D F, Bergelson J. 2001. Plant density and nutrient availability constrain constitutive and wound-induced expression of trypsin inhibitors in Brassica napus. Iournal of Chemical Ecology 27:593610.

Connell J H. 1990. Apparent versus "real" competition in plants. Pages 9-26 in Perspectives on Plant Competition, edited by J B Grace and D Tilman. San Diego (CA): Academic Press.

Connor E F, Faeth S H, Simberloff D, Opler P A. 1980. Taxonomic isolation and the accumulation of herbivorous insects: a comparison of introduced and native trees. Ecological Entomology 5:205-211.

Cook J M, Rokas A, Pagel M, Stone G N. 2002. Evolutionary shifts between host oak sections and hostplant organs in Andricus gallwasps. Evolution 56: 1821-1830.

Daehler C C. 2001. Darwin's naturalization hypothesis revisited. American Naturalist 158:324-330.

Darwin C. 1859. On the Origin of Species by Means of Natural Selection. London: J. Murray.

Dixon A F G, Kundu R. 1994. Ecology of host alternation in aphids. European Journal of Entomology 91:63-70.

Dolinger P M, Ehrlich P R, Fitch W L, Breedlove D E. 1973. Alkaloid and predation patterns in Colorado lupine populations. Oecologia 13:191-204.

Dussourd D E, Eisner T. 1987. Vein-cutting behavior: insect counterploy to the latex defense of plants. Science 237:898-900.

Ehrlich P R, Raven P H. 1964. Butterflies and plants: a study in coevolution. Evolution 18:586-608.

Elton C S. 1958. The Ecology of Invasions by Animals and Plants. London: Methuen.

Farrell B D, Dussourd D E, Mitter C. 1991. Escalation of plant defense: do latex and resin canals spur plant diversification? American Naturalist 138:881900.

Feeny P P. 1976. Plant apparency and chemical defense. Pages 1-40 in Biochemical Interaction between 
Plants and Insects, edited by $\mathrm{J}$ W Wallace and R L Mansell. New York: Plenum.

Fineblum W L, Rausher M D. 1995. Tradeoff between resistance and tolerance to herbivore damage in a morning glory. Nature 377:517-520.

Fox L R. 1981. Defense and dynamics in plantherbivore systems. American Zoologist 21:853-864.

Fox L R, Morrow P A. 1981. Specialization: species property or local phenomenon? Science 211:887893.

Fritz R S, Simms E L. 1992. Plant Resistance to Herbivores and Pathogens: Ecology, Evolution, and Genetics. Chicago (IL): University of Chicago Press.

Gardner S N, Agrawal A A. 2002. Induced plant defence and the evolution of counter-defences in herbivores. Evolutionary Ecology Research 4:11311151.

Giamoustaris A, Mithen R. 1995. The effect of modifying the glucosinolate content of oilseed rape (Brassica napus ssp. oleifera) on its interaction with specialist and generalist pests. Annals of Applied Biology 126:347-363.

Gould F. 2003. Bt-resistance management: theory meets data. Nature Biotechnology 21:1450-1451.

Gurevitch J, Scheiner S M, Fox G A. 2002. The Ecology of Plants. Sunderland (MA): Sinauer Associates.

Gurr G M, Wratten S D, Luna J M. 2003. Multi-function agricultural biodiversity: pest management and other benefits. Basic and Applied Ecology 4:107-116.

Hambäck P A, Ågren J, Ericson L. 2000. Associational resistance: insect damage to purple loosestrife reduced in thickets of sweet gale. Ecology 81:17841794.

Hambäck P A, Beckerman A P. 2003. Herbivory and plant resource competition: a review of two interacting interactions. Oikos 101:26-37.

Hambäck P A, Englund G. 2005. Patch area, population density and the scaling of migration rates: the resource concentration hypothesis revisited. Ecology Letters 8:1057-1065.

Hambäck P A, Pettersson J, Ericson L. 2003. Are associational refuges species-specific? FunctionalEcology 17:87-93.

Hawkins B A, Porter E E. 2003. Does herbivore diversity depend on plant diversity? The case of California butterflies. American Naturalist 161:40-49.

Hawthorne D J. 1997. Ecological history and evolution in a novel environment: habitat heterogeneity and insect adaptation to a new host plant. Evolution 51:153-162.

Hay M E. 1986. Associational plant defenses and the maintenance of species diversity: turning competitors into accomplices. American Naturalist 128: 617-641.

Hjältén J, Danell K, Lundberg P. 1993. Herbivore avoidance by association: vole and hare utilization of woody plants. Oikos 68:125-131.
Holt R D, Lawton J H. 1994. The ecological consequences of shared natural enemies. Annual Review of Ecology and Systematics 25:495-520.

Holzinger F, Wink M. 1996. Mediation of cardiac glycoside insensitivity in the monarch butterfly (Danaus plexippus): role of an amino acid substitution in the ouabain binding site of $\mathrm{Na}^{+}, \mathrm{K}^{+-}$ATPase. Iournal of Chemical Ecology 22:1921-1937.

Huffaker C B. 1958. Experimental studies on predation: dispersion factors and predator-prey oscillations. Hiloardia 27:343-383.

Iwao K, Rausher M D. 1997. Evolution of plant resistance to multiple herbivores: quantifying diffuse coevolution. American Naturalist 149:316-335.

Janz N, Nylin S. 1998. Butterflies and plants: a phylogenetic study. Evolution 52:486-502.

Janzen D H. 1980. When is it coevolution? Evolution 34:611-612.

Johnson M T J, Lajeunesse M J, Agrawal A A. 2006. Additive and interactive effects of plant genotypic diversity on arthropod communities and plant fitness. Ecology Letters 9:24-34.

Karban R, Agrawal A A. 2002. Herbivore offense. $\underline{A n-}$ nual Review of Ecology and Systematics 33:641-664.

Karban R, Baldwin I T. 1997. Induced Responses to Herbivory. Chicago (IL): University of Chicago Press.

Karban R, Brody A K, Schnathorst W C. 1989. Crowding and a plant's ability to defend itself against herbivores and diseases. American Naturalist 134: 749-760.

Knops J M H, Tilman D, Haddad N M, Naeem S, Mitchell C E, Haarstad J, Ritchie M E, Howe K M, Reich P B, Siemann E, Groth J. 1999. Effects of plant species richness on invasion dynamics, disease outbreaks, insect abundances and diversity. Ecology Letters 2:286-293.

Koricheva, J, Mulder C P H, Schmid B, Joshi J, HussDanell K. 2000. Numerical responses of different trophic groups of invertebrates to manipulations of plant diversity in grasslands. Oecologia 125: 271-282.

Kurashige N S, Agrawal A A. 2005. Phenotypic plasticity to light competition and herbivory in Chenopodium album (Chenopodiaceae). American Journal of Botany 92:21-26.

Lau J A. 2006. Evolutionary responses of native plants to novel community members. Evolution 60:5663.

Lau J A, Strauss S Y. 2005. Insect herbivores drive important indirect effects of exotic plants on native communities. Ecology 86:2990-2997.

Linhart Y B, Keefover-Ring K, Mooney K A, Breland B, Thompson J D. 2005. A chemical polymorphism in a multitrophic setting: thyme monoterpene composition and food web structure. American Naturalist 166:517-529.

Long Z T, Mohler C L, Carson W P. 2003. Extending 
the resource concentration hypothesis to plant communities: effects of litter and herbivores. Ecology 84:652-665.

Loreau M, Hector A. 2001. Partitioning selection and complementarity in biodiversity experiments. $\mathrm{Na}$ ture 412:72-76.

Milchunas D G, Noy-Meir I. 2002. Grazing refuges, external avoidance of herbivory and plant diversity. Oikos 99:113-130.

Mira A, Bernays E A. 2002. Trade-offs in host use by Manduca sexta: plant characters vs natural enemies. Oikos 97:387-397.

Mooney K A. 2003. Promylea lunigerella glendella Dyar (Pyralidae) feeds on both conifers and parasitic dwarf mistletoe (Arceuthobium spp.): one example of food plant shifting between parasitic plants and their hosts. Journal of the Lepidopterists' Society 57: 47-53.

Moran N A. 1992. The evolution of aphid life cycles. Annual Review of Entomology 37:321-348.

Morgan D C, Smith H. 1981. Non-photosynthetic responses to light quality. Pages 109-134 in Encylcopedia of Plant Physiology, New Series (Vol. 12A), edited by O L Lange, P S Nobel, C B Osmond, and $\mathrm{H}$ Ziegler. Berlin and New York: SpringerVerlag.

Morris R J, Lewis O T, Godfray H C J. 2004. Experimental evidence for apparent competition in a tropical forest food web. Nature 428:310-313.

Mulder C P H, Uliassi D D, Doak D F. 2001. Physical stress and diversity-productivity relationships: the role of positive interactions. Proceedings of the $\mathrm{Na}$ tional Academy of Sciences USA 98:6704-6708.

Murdoch W W, Evans F C, Peterson C H. 1972. Diversity and pattern in plants and insects. Ecology 53 : 819-829.

Murphy S M. 2004. Enemy-free space maintains swallowtail butterfly host shift. Proceedings of the National Academy of Sciences USA 101:18048-18052.

Nason J D, Heard S B, Williams F R. 2002. Hostassociated genetic differentiation in the goldenrod elliptical-gall moth, Gnorimoschema gallaesolidaginis (Lepidoptera: Gelechiidae). Evolution 56: 1475-1488.

Nokkala C, Nokkala S. 1998. Species and habitat races in the chrysomelid Galerucella nymphaeae species complex in northern Europe. Entomologia Experimentalis et Applicata 89:1-13.

Nosil P, Crespi B J, Sandoval C P. 2002. Host-plant adaptation drives the parallel evolution of reproductive isolation. Nature 417:440-443.

Pappers S M, van der Velde G, Ouborg N J. 2002a. Host preference and larval performance suggest host race formation in Galerucella nymphaeae. Oecologia 130:433-440.

Pappers S M, van der Velde G, Ouborg N J, van Groenendael J M. 2002b. Genetically based polymor- phisms in morphology and life history associated with putative host races of the water lily leaf beetle, Galerucella nymphaeae. Evolution 56:16101621.

Pennings S C, Silliman B R. 2005. Linking biogeography and community ecology: latitudinal variation in plant-herbivore interaction strength. Ecology 86:2310-2319.

Pfister C A, Hay M E. 1988. Associational plant refuges: convergent patterns in marine and terrestrial communities result from differing mechanisms. Oecologia 77:118-129.

Prieur-Richard A-H, Lavorel S, Linhart YB, Dos Santos A. 2002. Plant diversity, herbivory and resistance of a plant community to invasion in Mediterranean annual communities. Oecologia 130:96-104.

Rand T A. 2003. Herbivore-mediated apparent competition between two salt marsh forbs. Ecology 84:1517-1526.

Rand T A, Louda S M. 2004. Exotic weed invasion increases the susceptibility of native plants to attack by a biocontrol herbivore. Ecology 85:1548-1554.

Rausher M D. 1978. Search image for leaf shape in a butterfly. Science 200:1071-1073.

Rejmánek M. 1999. Invasive plant species and invasible ecosystems. Pages 79-102 in Invasive Species and Biodiversity Management, edited by O D Sandlund, P J Schei, and A Viken. Dordrecht (The Netherlands): Kluwer Academic Publishers.

Root R B. 1973. Organization of a plant-arthropod association in simple and diverse habitats: the fauna of collards (Brassica oleracea). Ecological Monographs 43:95-124.

Rousset O, Lepart J. 2002. Neighbourhood effects on the risk of an unpalatable plant being grazed. Plant Ecology 165:197-206.

Russell E P. 1989. Enemies hypothesis: a review of the effect of vegetational diversity on predatory insects and parasitoids. Environmental Entomology 18:590599.

Russell F L, Louda S M. 2005. Indirect interaction between two native thistles mediated by an invasive exotic floral herbivore. Oecologia 146:373-384.

Servedio M R, Noor M A F. 2003. The role of reinforcement in speciation: theory and data. Annual Review of Ecology Evolution and Systematics 34:339364.

Siemann E, Tilman D, Haarstad J, Ritchie M. 1998. Experimental tests of the dependence of arthropod diversity on plant diversity. American Naturalist 152:738-750.

Siemens D H, Garner S H, Mitchell-Olds T, Callaway R M. 2002. Cost of defense in the context of plant competition: Brassica rapa may grow and defend. Ecology 83:505-517.

Siemens D H, Lischke H, Maggiulli N, Schürch S, Roy B A. 2003. Cost of resistance and tolerance under 
competition: the defense-stress benefit hypothesis. Evolutionary Ecology 17:247-263.

Silvertown J, Dodd M. 1996. Comparing plants and connecting traits. Philosophical Transactions of the Roval Society of London B 351:1233-1239.

Singer M C. 1971. Evolution of food-plant preference in the butterfly Euphydryas editha. Evolution 25:383389.

Singer M C. 1983. Determinants of multiple host use by a phytophagous insect population. Evolution 37:389-403.

Singer M C, Parmesan C. 1993. Sources of variation in patterns of plant-insect association. Nature 361: 251-253.

Singer M C, Thomas C D, Billington H L, Parmesan C. 1989. Variation among conspecific insect populations in the mechanistic basis of diet breadth. Animal Behaviour 37:751-759.

Singer M C, Thomas C D, Parmesan C. 1993. Rapid human-induced evolution of insect-host associations. Nature 366:681-683.

Singer M C, Wee B. 2005. Spatial pattern in checkerspot butterfly: host plant association at local, metapopulation and regional scales. Annales Zoologici Fennici 42:347-361.

Singer M S. 2001. Determinants of polyphagy by a woolly bear caterpillar: a test of the physiological efficiency hypothesis. Oikos 93:194-204.

Singer M S, Bernays E A, Carrière Y. 2002. The interplay between nutrient balancing and toxin dilution in foraging by a generalist insect herbivore. Animal Behaviour 64:629-643.

Singer M S, Carrière Y, Theuring C, Hartmann T. 2004. Disentangling food quality from resistance against parasitoids: diet choice by a generalist caterpillar. American Naturalist 164:423-429.

Singer M S, Stireman J O, III. 2003. Does anti-parasitoid defense explain host-plant selection by a polyphagous caterpillar? Oikos 100:554-562.

Solarz S L, Newman R M. 1996. Oviposition specificity and behavior of the watermilfoil specialist Euhrychiopsis lecontei. Oecologia 106:337-344.

Stiling P, Rossi A M, Cattell M V. 2003. Associational resistance mediated by natural enemies. Ecological Entomology 28:587-592.

Stireman J O, III, Nason J D, Heard S B, Seehawer J M. 2006. Cascading host-associated genetic differentiation in parasitoids of phytophagous insects. Proceedings of the Roval Society of London B 273:523530.

Strauss S Y, Agrawal A A. 1999. The ecology and evolution of plant tolerance to herbivory. Trends in Ecology and Evolution 14:179-185.

Strauss S Y, Irwin R E. 2004. Ecological and evolutionary consequences of multispecies plant-animal interactions. Annual Review of Ecology, Evolution, and Svstematics 35:435-466.
Strauss S Y, Sahli H, Conner J K. 2005. Toward a more trait-centered approach to diffuse (co)evolution. New Phytologist 165:81-89.

Strong D R, Lawton J H, Southwood R. 1984. Insects on Plants: Community Patterns and Mechanisms. Cambridge (MA): Harvard University Press.

Tahvanainen J O, Root R B. 1972. The influence of vegetational diversity on the population ecology of a specialized herbivore, Phyllotreta cruciferae (Coleoptera: Chrysomelidae). Oecologia 10:321-346.

Thies C, Roschewitz I, Tscharntke T. 2005. The landscape context of cereal aphid-parasitoid interactions. Proceedings of the Roval Society of London $B$ 272:203-210.

Thomas C D, Ng D, Singer M C, Mallet J L B, Parmesan C, Billington H L. 1987. Incorporation of a European weed into the diet of a North American herbivore. Evolution 41:892-901.

Thompson J N. 1988. Variation in interspecific interactions. Annual Review of Ecology and Systematics 19:65-87.

Thompson J N. 1994. The Coevolutionary Process. Chicago (IL): University of Chicago Press.

Thompson J N. 1999. Specific hypotheses on the geographic mosaic of coevolution. American Naturalist 153(Supplement):S1-S14.

Tiffin P. 2002. Competition and time of damage affect the pattern of selection acting on plant defense against herbivores. Ecology 83:1981-1990.

Tonhasca A, Jr, Byrne D N. 1994. The effects of crop diversification on herbivorous insects: a meta-analysis approach. Ecological Entomology 19:239-244.

Tuomi J, Augner M. 1993. Synergistic selection of unpalatability in plants. Evolution 47:668-672.

Turchin P. 1989. Population consequences of aggregative movement. Journal of Animal Ecology 58:75100.

Uriarte M, Canham C D, Root R B. 2002. A model of simultaneous evolution of competitive ability and herbivore resistance in a perennial plant. Ecology 83:2649-2663.

van Dam N M, Baldwin I T. 1998. Costs of jasmonateinduced responses in plants competing for limited resources. Ecology Letters 1:30-33.

Vandermeer J. 1989. The Ecology of Intercropping. Cambridge and New York: Cambridge University Press.

Vellend M. 2006. The consequences of genetic diversity in competitive communities. Ecology 87:304-311.

Vellend M, Geber M A. 2005. Connections between species diversity and genetic diversity. Ecology Letters 8:767-781.

Via S, Hawthorne D J. 2002. The genetic architecture of ecological specialization: correlated gene effects on host use and habitat choice in pea aphids. American Naturalist 159(Supplement):S76-S88.

Vet L E M, Dicke M. 1992. Ecology of infochemical use 
by natural enemies in a tritrophic context. Annual Review of Entomology 37:141-172.

Weis A E, Hochberg M E. 2000. The diverse effects of intraspecific competition on the selective advantage to resistance: a model and its predictions. American Naturalist 156:276-292.

White J A, Whitham T G. 2000. Associational susceptibility of cottonwood to a box elder herbivore. Ecology 81:1795-1803.

Wiklund C. 1984. Egg-laying patterns in butterflies in relation to their phenology and the visual apparency and abundance of their host plants. Oecologia 63:23-29.

Wimp G M, Young W P, Woolbright S A, Martinsen G D, Keim P, Whitham T G. 2004. Conserving plant genetic diversity for dependent animal communities. Ecology Letters 7:776-780.

Wootton J T. 1994. The nature and consequences of indirect effects in ecological communities. Annual Review of Ecology and Systematics 25:443-466.

Yukawa J, Uechi N, Horikiri M, Tuda M. 2003. Description of the soybean pod gall midge, Asphondylia yushimai sp. n. (Diptera: Cecidomyiidae), a major pest of soybean and findings of host alternation. Bulletin of Entomological Research 93:73-86.

Zangerl A R, Berenbaum M R. 2003. Phenotype matching in wild parsnip and parsnip webworms: causes and consequences. Evolution 57:806-815.

Zimmerman E C. 1960. Possible evidence of rapid evolution in Hawaiian moths. Evolution 14:137-138. 